TUMOR CELLS CAN ADOPT THE PHENOTYPE OF STROMAL CELLS BY CELL FUSION

$\mathrm{PhD}$ thesis

Zsuzsanna Kurgyis MD 


\title{
TUMOR CELLS CAN ADOPT THE PHENOTYPE OF STROMAL CELLS BY CELL FUSION
}

PhD thesis

\author{
Zsuzsanna Kurgyis MD \\ Supervisor: István Balázs Németh MD PhD \\ Graduate School of Clinical Medicine \\ Department of Dermatology and Allergology \\ University of Szeged \\ Szeged, Hungary
}




\section{ARTICLES DIRECTLY RELATED TO THE SUBJECT OF THE THESIS:}

I. Kurgyis $\mathbf{Z}^{*}$, Kemény $\mathrm{LV}^{*}$, Buknicz T, Groma G, Oláh J, Jakab Á, Polyánka H, Zänker K, Dittmar T, Kemény L, Németh IB. Melanoma-Derived BRAF(V600E) Mutation in Peritumoral Stromal Cells: Implications for in Vivo Cell Fusion. Int J Mol Sci. 2016 Jun 21;17(6). (*these authors contributed equally) IF: 3.226

II. Kemény LV*, Kurgyis Z*, Buknicz T, Groma G, Jakab Á, Zänker K, Dittmar T, Kemény L, Németh IB. Melanoma Cells Can Adopt the Phenotype of Stromal Fibroblasts and Macrophages by Spontaneous Cell Fusion in Vitro. Int J Mol Sci. 2016 Jun 2;17(6). (*these authors contributed equally) IF: 3.226 


\section{INHALT}

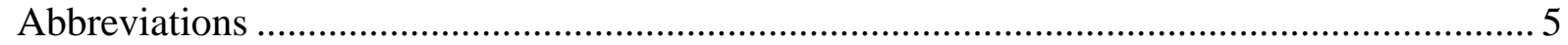

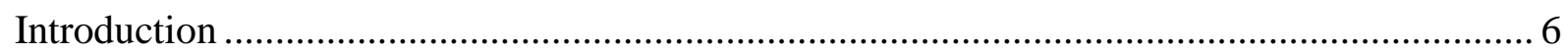

Role of tumor heterogeneity in tumor progression................................................... 6

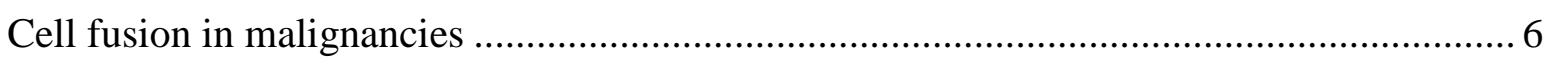

Investigation of spontaneous and induced cell fusion events ..................................... 6

Cell fusion as a potential mechanism contributing to tumor heterogeneity .......................... 7

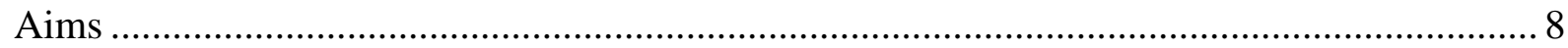

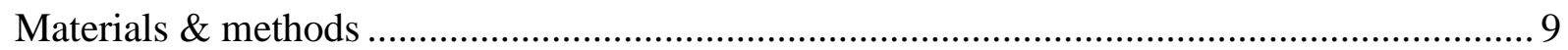

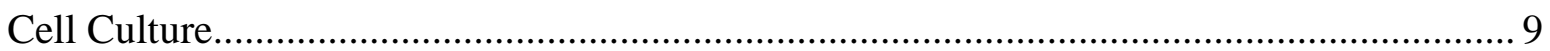

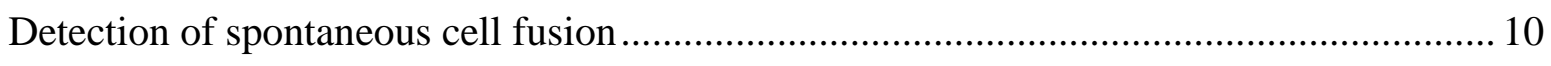

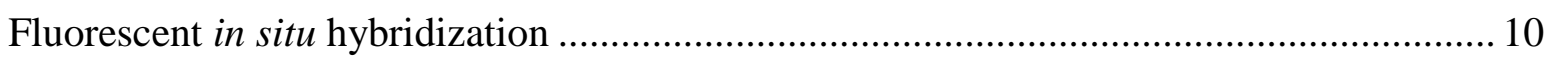

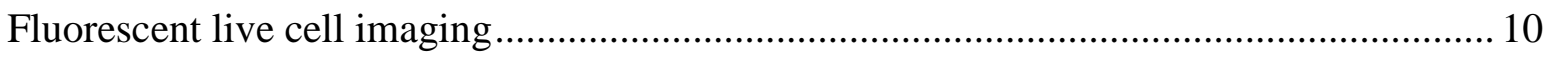

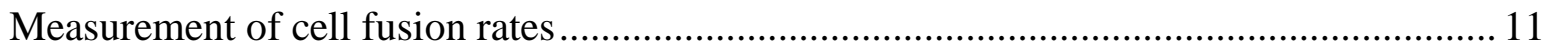

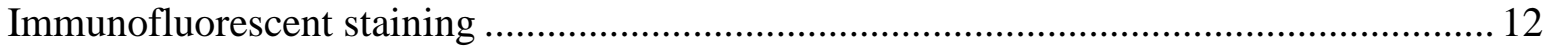

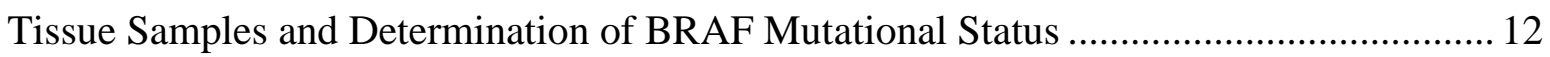

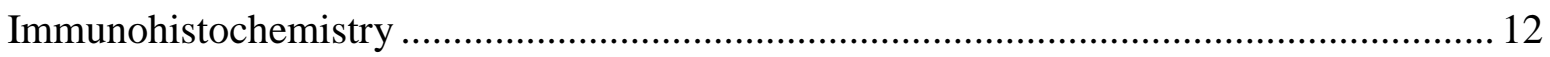

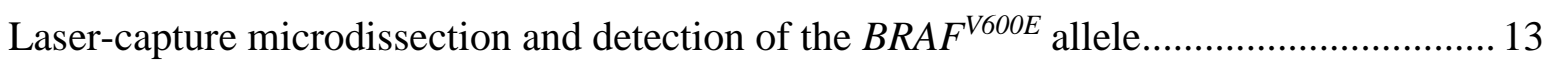

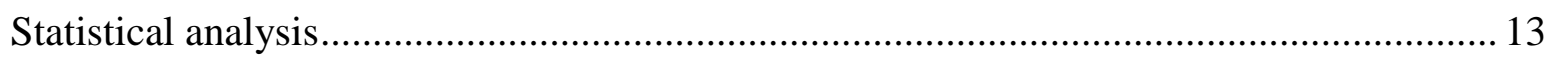

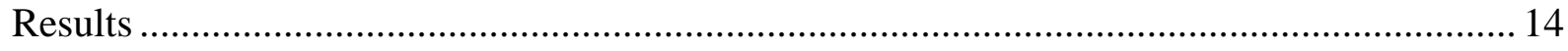

$\mathrm{BRAF}^{\mathrm{V} 600 \mathrm{E}}$ protein is expressed in subpopulations of peritumoral stromal cells ................. 14

Some peritumoral fibroblasts and macrophages carry the $\mathrm{BRAF}^{\mathrm{V} 600 \mathrm{E}}$ mutation in primary melanoma, melanoma metastasis and a tumor-free re-excision sample .............................. 16

Melanoma cells spontaneously fuse with fibroblasts and monocytes in vitro..................... 19

Hybrid cells are indistinguishable from stromal cells based on cell morphology and

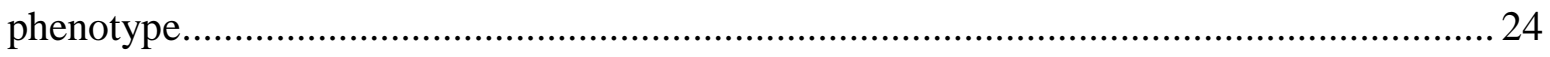

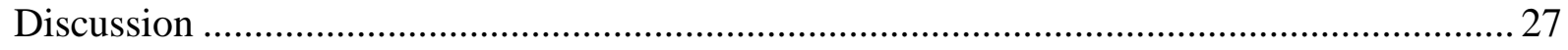

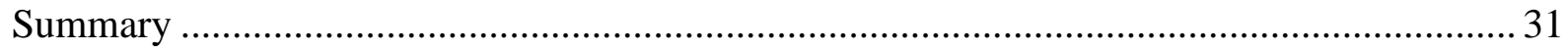

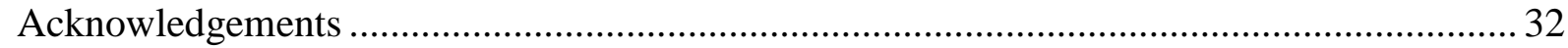

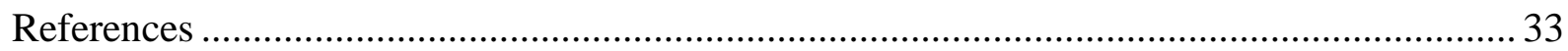


ABBREVIATIONS

The following abbreviations are used in this manuscript:

CTG CellTracker Green ${ }^{\circledR}$

CTO CellTracker Orange ${ }^{\circledR}$

DAPI 4',6-Diamidin-2-phenylindol

FISH fluorescent in situ hybridization

MART1 melanoma antigen recognized by T-cells

PFA paraformaldehyde

SMA smooth muscle actin 


\section{INTRODUCTION}

\section{Role of tumor heterogeneity in tumor progression}

Cutaneous melanoma is a highly aggressive malignancy, which often gives rise to metastases and local recurrences following series of tumor-free staging [1,2]. The histopathological examination of excisional and re-excisional samples together with sentinel lymph node biopsies constitutes a fundamental part of the prognostic evaluation of this disease. Thus, the ability to detect recurrent-tumor-initiating cells in the tissue sample is highly important for prognostic purposes as well as managing this disease.

As a result of tumor heterogeneity, tumor cells often differentially express phenotypic markers [3,4], rendering their detection during routine histological assessments difficult. Epithelial-mesenchymal transition, dedifferentiation and acquisition of stem-cell characteristics have been shown to make tumor cells more malignant $[3,5,6]$. Although the mechanisms by which these features are acquired have not yet been fully elucidated, epigenomic and genomic alterations are thought to be the key drivers for malignant heterogeneity $[7,8]$.

\section{Cell fusion in malignancies}

An increasing body of evidence indicates that cell fusion has not only a physiological role during tissue development and repair, but might also be a hidden force promoting tumor progression[9-13]. Fibroblasts, mesenchymal stem cells and macrophages have been proposed as fusion partners of tumor cells[14-16] and several studies have demonstrated that tumor-stromal hybrid cells mostly display more malignant properties than parental tumor cells $[17,18]$.

\section{Investigation of spontaneous and induced cell fusion events}

Most cell fusion studies are based on experiments on hybrid cells that originate from a single hybrid clone generated with electro- or chemical fusion followed by antibiotic selection. There are only a few studies focusing on spontaneous cell-cell fusion, which is a wellprogrammed event that requires a specific controlling system[19]. By artificially generating hybrid cells, there is the possibility that unique and important characteristics of hybrid cells 
might not be discovered. Furthermore, precise analysis of hybrid cell morphology and phenotype might also differ in spontaneous and programmed events.

\section{Cell fusion as a potential mechanism contributing to tumor heterogeneity}

Numerous studies have suggested that cell fusion may contribute to tumor heterogeneity[2023], moreover, Terada et al. have shown that bone marrow derived stem cells can adopt the phenotype of other cells by cell fusion[24]. Therefore, we hypothesized that tumor cells could similarly adopt a stromal phenotype by fusing with peritumoral stromal cells, while maintaining oncogenic properties. Such fusion may lead to a cell type with mixed features that may evade immune recognition and clinical and histopathological detection and, therefore, promote tumor recurrence. Thus, the detection of these hybrid cells in the intra- and peritumoral stroma could be significant for the accurate histopathological diagnosis, prognosis and subsequent therapy. 


\section{AIMS}

I. Our aim was therefore to identify potential recurrent tumor-initiating cells in the tumor stroma that display an altered tumor marker expression and therefore stay hidden during histological examinations of tissue samples in melanoma patients.

II. Moreover, we wanted to investigate if spontaneous tumor-stromal cell fusion can lead to the development of such hybrid cells in vitro. 


\section{MATERIALS \& METHODS}

\section{Cell Culture}

The human melanoma cell lines A375, G361, UACC-257, and SK-MEL-2 were kindly provided by Krisztina Buzás. All cell lines were authenticated using short tandem repeat analysis (Microsynth AG, Balgach, Switzerland) after finishing all experiments. Primary human monocytes were obtained from peripheral blood and isolated using MagCellect Human CD14+ Cell Isolation Kit (R\&D Systems, Minneapolis, MN, USA) following gradient centrifugation with Ficoll-Paque (GE Healthcare Life Sciences, Chalfont St Giles, UK). Human dermal fibroblasts were obtained from healthy individuals undergoing plastic surgery with the approval of the local institutional review board and after signing an informed consent. Skin samples were incubated in dispase solution overnight at $4{ }^{\circ} \mathrm{C}$. After the removal of the epidermis, the dermis was incubated in a digestion medium (10.8 $\mathrm{mg}$ collagenase, $5 \mathrm{mg}$ hyaluronidase, $0.4 \mathrm{mg}$ deoxyribonuclease, and $0.1 \mathrm{~mL}$ fetal bovine serum diluted in $4 \mathrm{~mL}$ DMEM low glucose medium) for two hours at $37{ }^{\circ} \mathrm{C}$ and filtered through a $100-\mu \mathrm{m}$ cell strainer.

Each melanoma cell line stained with $6 \mu \mathrm{mol} / \mathrm{mL}$ CellTracker Orange (CMTMR) was mixed either with fibroblasts or with freshly isolated monocytes labeled with 10 and $4 \mu \mathrm{mol} / \mathrm{mL}$ CellTracker Green (CMFDA, both from Life Technologies, Carlsbad, CA, USA), respectively, and grown in co-cultures for $24 \mathrm{~h}$. The fibroblast-containing co-cultures were grown in low glucose DMEM supplemented with 5\% fetal bovine serum, while the monocyte-containing co-cultures in RPMI 1640 (HEPES modification) with 10\% fetal bovine serum and $30 \mathrm{IU} / \mathrm{mL}$ GMCSF (R\&D Systems). All growth media were supplemented with $1 \%$ Penicillin/Streptomycin and 1\% Glutamine. All cell culture reagents used are products of Lonza (Basel, Switzerland), if not specified otherwise.

For confocal microscopic visualization 100,000 melanoma cells were seeded either with 200,000 fibroblasts or with 300,000 monocytes on 1-well Lab-Tek ${ }^{\circledR}$ II Chamber Slides ${ }^{\mathrm{TM}}$ (Sigma-Aldrich, St. Louis, MI, USA); for flow cytometric analyses, 20,000 melanoma cells either with 40,000 fibroblasts or with 60,000 monocytes were seeded onto 12-well plates (Corning, Corning, NY, USA). 


\section{Detection of spontaneous cell fusion}

Co-cultures fixed with 4\% paraformaldehyde (PFA) were visualized with Fluoview 1000 (Olympus, Tokyo, Japan) confocal laser-scanning microscope with a 40× oil immersion objective. Excitation/emission wavelengths were 405/461, 488/519, and 543/567 nm for DAPI (4',6-Diamidin-2-phenylindol), CTG, and CTO, respectively. For Z stacking, step size was set to $1 \mu \mathrm{m}$. All fluorescent image analyses and three-dimensional reconstructions were performed with ImageJ software (National Insitutes of Health, Bethesda, MD, USA).

\section{Fluorescent in situ hybridization (FISH)}

Hybrid cells in PFA-fixed co-cultures were identified using AxioImager.Z1 epifluorescent microscope, AxioCamMR3 camera (both from Carl Zeiss Microscopy, Jena, Germany) and 40x oil immersion objective. Excitation/emission filters were set to 353/465, 495/519, and 558/575 nm for DAPI, CTG, and CTO, respectively. After the removal of cover slips, samples were fixed again with 3:1 ratio of methanol and acetate acid followed by photobleaching using Suntest CPS+ Tabletop Xenon Exposure Systems (Thermo Fischer Scientific, Waltham, MA, USA). The monocyte-containing co-cultures were digested using $0.01 \mathrm{~N} \mathrm{HCl}, 0.005 \%$ pepsin, and fixed with PFA. All samples were incubated in $70 \%$ formamide in 2xSSC at 95 ${ }^{\circ} \mathrm{C}$, then in $70 \%, 80 \%$, and absolute alcohol each and dried. The $\mathrm{X}$ and Yc dual label fluorescent probes (Reagens Ltd., Pécs, Hungary) were put on the samples, denatured at 72 ${ }^{\circ} \mathrm{C}$, and incubated overnight at $37^{\circ} \mathrm{C}$. Then, samples were washed with $0.3 \% \mathrm{NP}-40$ in $2 \mathrm{xSSC}$ and incubated in $0.3 \% \mathrm{NP}-40$ in $0.4 \mathrm{xSSC}$ at $72{ }^{\circ} \mathrm{C}$. FISH signals were visualized with Fluoview 1000 confocal laser-scanning microscope. Excitation/emission wavelengths were 488/519 and 543/567 $\mathrm{nm}$ for $\mathrm{X}$ and $\mathrm{Y}$ chromosomes, respectively.

\section{Fluorescent live cell imaging}

Co-cultures grown for $12 \mathrm{~h}$ were put into the chamber of a Fluoview 10i-W confocal laserscanning microscope (Olympus). Excitation/emission wavelengths were 473/519 and 559/567 $\mathrm{nm}$ for CTG and CTO, respectively. Five Z-stack images with $3-\mu \mathrm{m}$ step sizes were taken every $60 \mathrm{~min}$ for $12 \mathrm{~h}$ at 90 randomly chosen regions using 60x magnification. 


\section{Measurement of cell fusion rates}

Co-cultures fixed with PFA and stained with DAPI were analyzed in a CyFlow $®$ Space flow cytometer (Sysmex Partec GmbH, Görlitz, Germany). DAPI, CellTracker Green, and CellTracker Orange were detected on channels FL10, FL1, and FL12, respectively. Gating is shown in Figure 1.
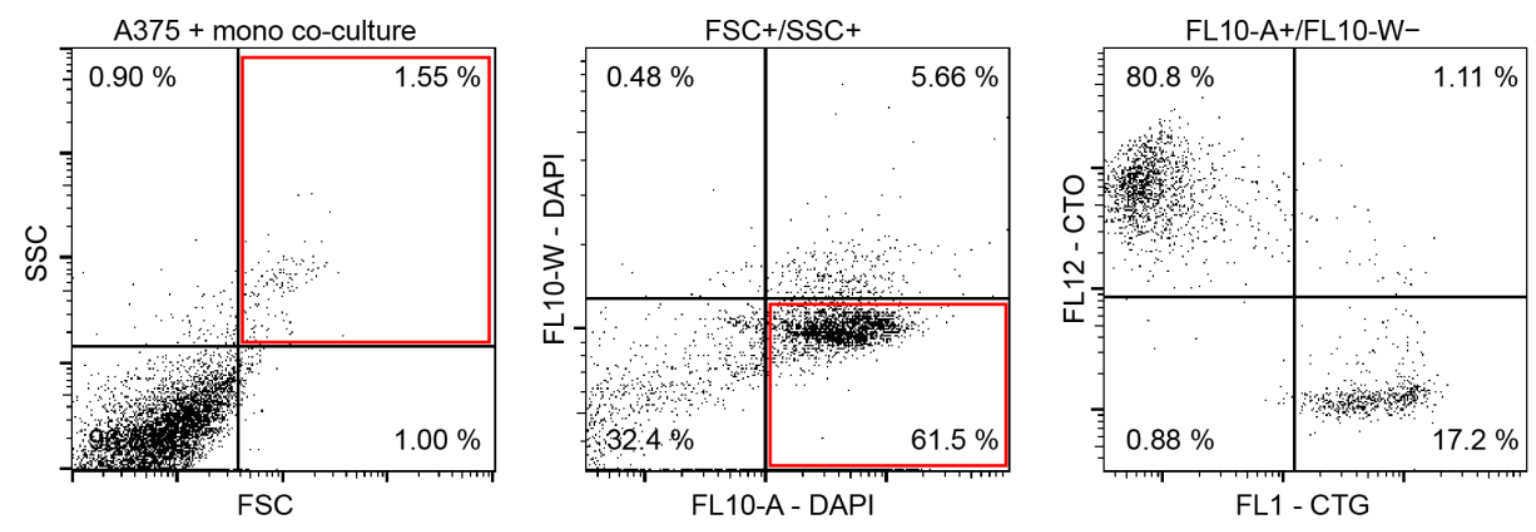

Figure 1. Gating mechanisms in flow cytometry for the measurement of cell fusion rates. Representative dot plots of an A375-monocyte co-culture. In the forward scatter (FSC) - side scatter (SSC) plot (left panel) cell debris is excluded upon gating the events in the upper right quadrant. In the FL10-A - FL10-W plot (middle panel) only the FSC+/SSC+ events are displayed. FL10-A- cells are considered as apoptotic cells while FL10-W+ cells as cell doublets and are therefore excluded. Only FL10-A+/ FL10-W-cells are displayed in the CellTracker Green (CTG) - CellTracker Orange (CTO) plot (right panel), in which $C T G+/ C T O-$ cells are monocytes and $C T G-/ C T O+$ cells are melanoma cells.

Assuming that double positive cells in a co-culture result not only from cell fusion, we used transwell cultures for controls, in which monocytes were separated from melanoma cells by a Transwell@ (Corning) with a pore size of $3.0 \mu \mathrm{m}$; thus, small, stained dead cell particles could cross the membrane but intact cells could not fuse. Therefore, fusion rate was determined as the rate of double positive cells detected in transwell cultures subtracted from that of co-cultures. All data were analyzed using FlowJo software (FlowJo, Ashland, OR, USA). 


\section{Immunofluorescent staining}

Co-cultures were fixed with PFA. High (for MART1) or low (for CD68) pH target retrieval solution (DAKO, Glostrup, Denmark) was used for heat-induced epitope retrieval. 50\% heatinactivated serum of the monocyte donor was used to block Fc receptors on monocytes and $1 \%$ goat serum to prevent the nonspecific binding of the secondary antibody. MART1 (clone 103, 1:200) and CD68 (clone PG-M1, 1:100) mouse monoclonal antibodies (all from DAKO) and their appropriate isotype controls: mouse anti-human IgG1 and IgG3 (both from Biolegend, San Diego, CA, USA) were labeled with goat anti-mouse Alexa 647 antibody (Life Technologies, 1:400). All the reagents were diluted in tris-buffered saline containing 1\% bovine serum albumin and, for monocyte-containing co-cultures, $50 \%$ heat-inactivated serum of the monocyte donor.

Immunofluorescent stainings were visualized with epifluorescent microscopy. Excitation/emission filters were set to $653 / 668 \mathrm{~nm}$ for Alexa 647.

\section{Tissue Samples and Determination of BRAF Mutational Status}

Tissue samples from $\mathrm{n}=11$ patients with $\mathrm{BRAF}^{\mathrm{V} 600 \mathrm{E}}$ and $\mathrm{n}=5$ patients with $B R A F^{W T}$ melanoma were examined for $\mathrm{BRAF}^{\mathrm{V} 600 \mathrm{E}}$ protein expression. The corresponding patient numbers for genetic analyses were $\mathrm{n}=11$ in the case of $B R A F^{V 600 E}$ melanoma and $\mathrm{n}=8$ in the case of $B R A F^{W T}$ melanoma. The $B R A F$ mutational status of melanomas was determined with cobas ${ }^{\circledR} 4800$ BRAF $^{\mathrm{V} 600}$ Mutation Test (Roche Molecular Diagnostics, Pleasanton, CA, USA).

\section{Immunohistochemistry}

Formalin-fixed, paraffin-embedded tissue sections of patients with $B R A F^{V 600 E}$ malignant melanoma were stained with rabbit monoclonal MART1 (clone A19P, DB Biotech, Kosice, Slovakia), mouse monoclonal SMA (clone 1A4, DAKO, Glostrup, Denmark), CD68 (clone PGM1, DAKO), and BRAF ${ }^{\mathrm{V} 600 \mathrm{E}}$ (Clone VE1, Springbio, Pleasanton, CA, USA) primary antibodies. The Bond Polymer Refine Detection Kit and the ChromoPlex 1 Dual Detection Kit (both from Leica, Wetzlar, Germany) were used for the visualization of single and dual histochemical staining, respectively, according to the manufacturer's instructions. All immunohistochemical staining was scanned with a Pannoramic MIDI Slide Scanner (3DHISTECH Ltd., Budapest, Hungary) and analyzed with Pannoramic Viewer software (3DHISTECH Ltd.) 


\section{Laser-capture microdissection and detection of the $B R A F^{V 600 E}$ allele}

30-100 cells were dissected from tissue sections stained either with MART1 and SMA or with MART1 and CD68 using a Palm Microbeam (Carl Zeiss Microscopy, Jena, Germany). Samples were digested with proteinase K (QIAGEN, Venlo, The Netherlands). Mutant allele (BRAF_476_mu) and gene reference (Braf_rf) TaqMan® Mutation Detection Assays (Life Technologies, Carlsbad, CA, USA) were used to detect the $B R A F^{V 600 E}$ mutant allele in the dissected samples. Samples with $\Delta \mathrm{Ct}\left(\mathrm{Ct}_{\mathrm{mut}}-\mathrm{Ct}_{\mathrm{ref}}\right)<8$ and $\mathrm{Ct}_{\mathrm{mut}}<40$ were considered carrying the mutant allele. MART1+ tumor cells dissected from $B R A F^{W T}$ and $B R A F^{V 600 E}$ melanoma were used as negative and positive controls, respectively.

\section{Statistical analysis}

One-way Analysis of Variance and Bonferroni post hoc tests were used to compare the means of fusion rates in different melanoma cell lines. Local recurrence rate in melanoma patients were compared with Fisher's exact test. Level of significance was set to 0.05 . 


\section{RESULTS}

\section{$\mathrm{BRAF}^{\mathrm{V} 600 \mathrm{E}}$ protein is expressed in subpopulations of peritumoral stromal cells}

To identify potential recurrent tumor-initiating cells, we screened for peritumoral cells that display a stromal phenotype but carry tumor-derived oncogenic information. For this we performed dual immunohistochemical staining on $n=11$ patient-derived tissue samples of $B R A F^{V 600 E}$ melanoma with MART1 (melanoma antigen recognized by T-cells) and $\mathrm{BRAF}^{\mathrm{V} 600 \mathrm{E}}$. BRAF ${ }^{V 600 E}$ is an oncogenic somatic mutation present in approximately $50 \%-60 \%$ of malignant melanomas. The staining revealed that, in addition to melanoma cells, $\mathrm{BRAF}^{\mathrm{V} 600 \mathrm{E}}$ is also expressed in some subpopulations of MART1- peritumoral stromal cells with fibroblast and macrophage morphology (Figure 2).
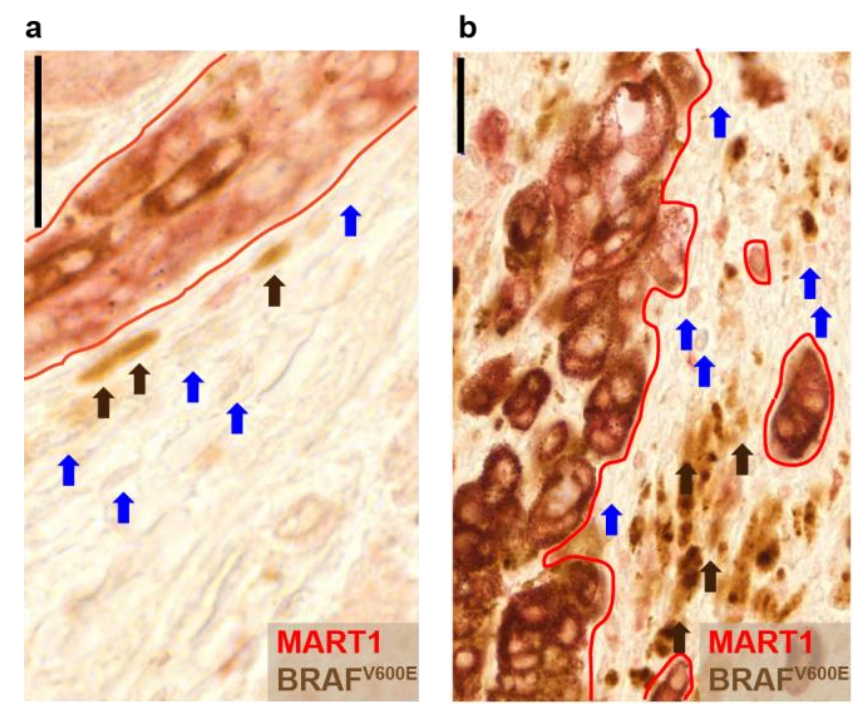

Figure 2. Peritumoral stromal cells express the melanoma-derived oncogenic BRAF V600E protein. $(\boldsymbol{a}, \boldsymbol{b})$ Tissue samples of a patient with BRAF $F^{V 600}$ melanoma stained for the melanoma marker melanoma antigen recognized by T-cells (MART1) (red), the BRAFV600E mutant protein (brown) and hematoxylin (blue). Brown arrows indicate peritumoral $M A R T 1-/ B R A F^{V 600 E}+$ cells displaying fibroblast $(\boldsymbol{a})$ or macrophage $(\boldsymbol{b})$ morphology. Blue arrows indicate MART1-/BRAF ${ }^{V 600 E_{-}}$stromal cells (light blue from hematoxylin). Red lines indicate MART1+ melanoma cells. Black bars indicate $50 \mu \mathrm{m}$.

To investigate whether the mutant protein originated from the tumor cells, we tested the stroma of $n=5 B R A F^{W T}$ melanomas for the presence of the $\mathrm{BRAF}^{\mathrm{V} 600 \mathrm{E}}$ protein. However, we 
could not detect the mutant protein in $B R A F^{W T}$ melanoma tissue samples (Figure 3), suggesting that the presence of the mutation in the stromal cells could not occur without the neighboring melanoma cells carrying the mutation. Nevertheless, though the antibody has been reported to be highly specific, and we did not see any specific signals in $B R A F^{W T}$ melanoma tissue samples, we cannot rule out nonspecific staining especially in case of macrophages.

a

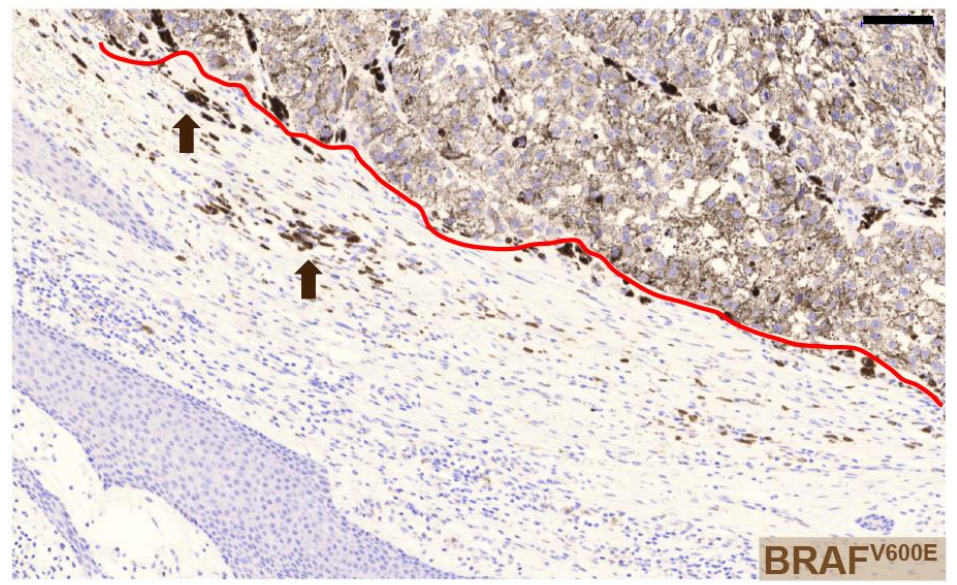

b

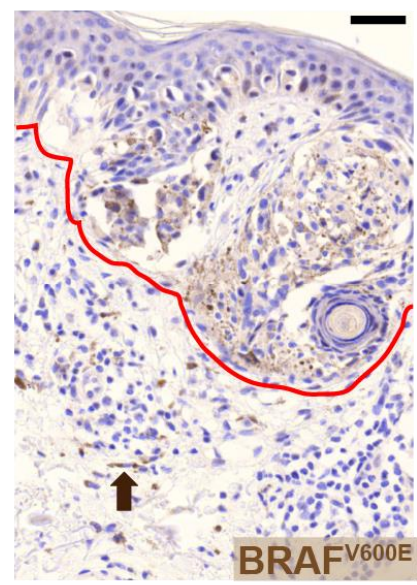

C

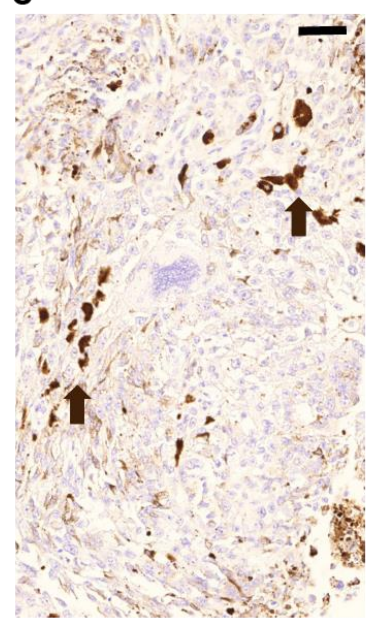

d

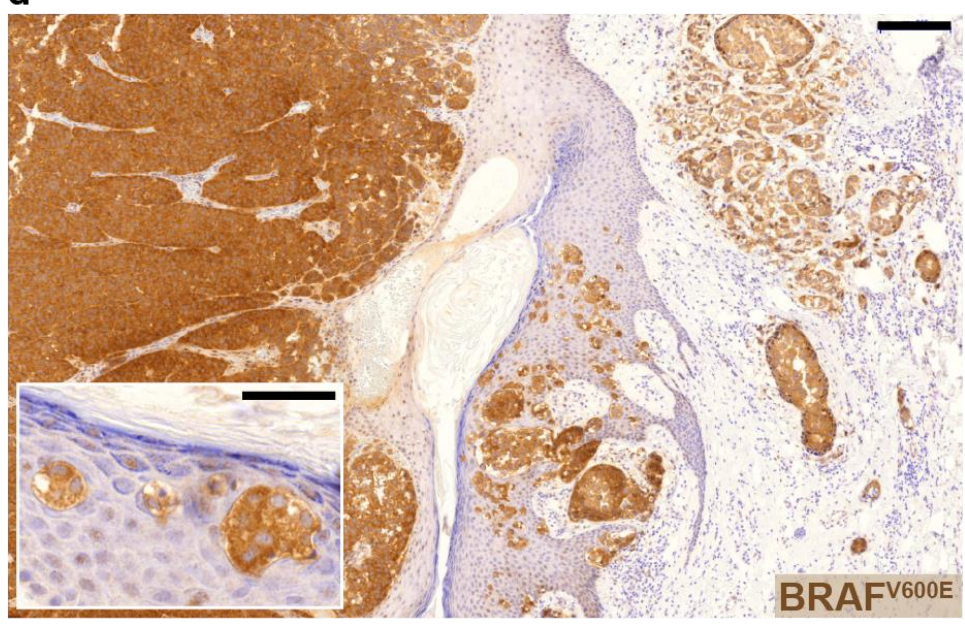

Figure 3. $B R A F^{V 600 E}$ is not expressed in peritumoral stromal cells of $B R A F^{W T}$ melanoma. (a-b) BRAF $F^{W T}$ melanoma tissue sample stained with BRAF ${ }^{V 600 E}$ (light brown) and hematoxylin (blue) (c) BRAF $F^{W T}$ melanoma tissue sample stained without primary antibody. (d) BRAF $\boldsymbol{F}^{\text {Vo00E }}$ melanoma tissue sample stained with BRAFV600E (light brown) and hematoxylin (blue). Red lines demarcate tumor cells and brown arrows indicate dark brown granules that correspond to melanin pigments. Scale bars indicate $100 \mu \mathrm{m}(\boldsymbol{a}), 50 \mu \mathrm{m}(\boldsymbol{b}, \boldsymbol{c}$ and $\boldsymbol{d}$ small panel) and 200 $\mu m$ (d large panel). 
Some peritumoral fibroblasts and macrophages carry the $B R A F^{V 600 E}$ mutation in primary melanoma, melanoma metastasis and a tumor-free re-excision sample

We wanted to confirm that the staining we observed in the $B R A F^{V 600 E}$ samples was specific, so we examined whether this oncogenic information is also present in the peritumoral cells at the genetic level. Therefore, we dual-stained $B R A F^{V 600 E}$ primary melanoma tissue samples with MART1 and either the fibroblast marker smooth muscle actin (SMA) or the monocytemacrophage marker CD68, and isolated cell compartments consisting of 20-50, clearly MART1- but either SMA+ or CD68+ cells with fibroblast and macrophage morphology, respectively, using laser-capture microdissection (Figure 4a,b). Subsequent allele specific mutation detection PCR analyses performed on the dissected stromal cells revealed that the $B R A F^{V 600 E}$ mutant allele was present in peritumoral MART1-/SMA+ fibroblasts and MART1-/CD68+ macrophages. In addition to primary melanoma tissue samples, such peritumoral stromal cells carrying the melanoma-derived mutation were detected in lymph node and cutaneous melanoma metastases (Figure 4c). Surprisingly, $B R A F^{V 600 E}$ was also detected when analyzing MART1- macrophages dissected from a histologically tumor-free re-excision sample from a patient who subsequently developed a local recurrence. 

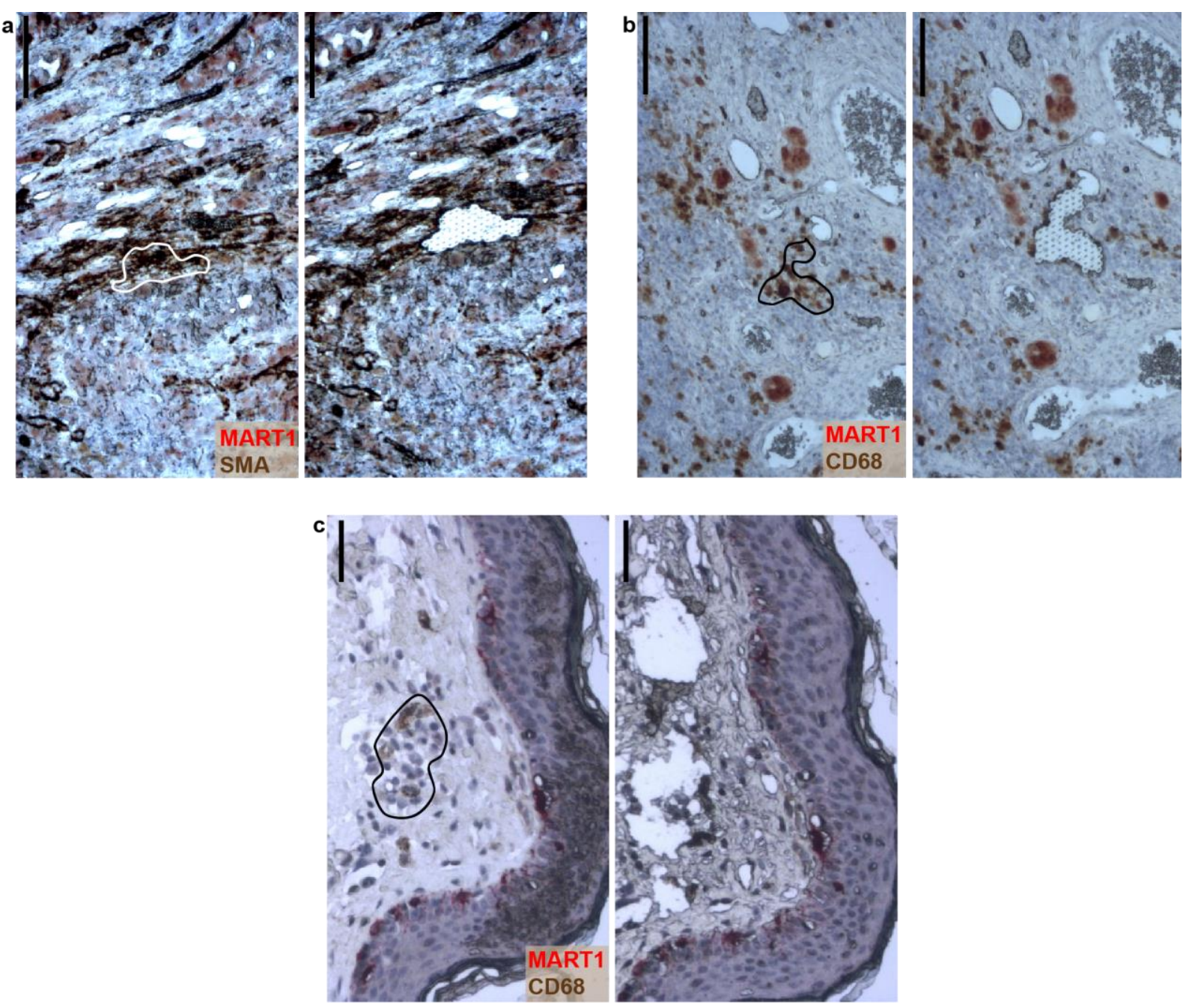

Figure 4. Peritumoral stromal cells contain the melanoma-derived oncogenic BRAF ${ }^{V 600 E}$ at the genomic level. (a) BRAF ${ }^{V 600 E}$ melanoma tissue sample stained for MART1 (red), smooth muscle actin (SMA) (brown), and hematoxylin (blue) before (left panel) and after (right panel) laser-capture microdissection of MART1-/SMA+ fibroblasts (white line). (b,c) Tissue samples of BRAF V600E (b) primary melanoma and (c) melanoma metastasis stained for MART1 (red), CD68 (brown), and hematoxylin (blue) before (left panels) and after (right panels) laser-capture microdissection of MART1-/CD68+ macrophages (black line). Black bars indicate $150 \mu \mathrm{m}$. 
Having dissected peritumoral stromal cells from $B R A F^{W T}$ melanoma tissue samples, we only detected the wild-type allele, providing further evidence that $B R A F^{V 600 E}$ is only present in peritumoral cells that are adjacent to a mutant tumor. In total, we examined 86 dissected samples of 19 patients, and out of 12 patients with $B R A F^{V 600 E}$ melanoma, we found $B R A F^{V 600 E}$-containing peritumoral cells in the tissue samples of five patients. The proportion of mutant alleles detected in these cell populations varied between $0.5 \%$ and $30 \%$ (Table 1).

\begin{tabular}{ccc}
\hline & \multicolumn{2}{c}{$N_{\text {pos }} / N_{\mathbf{e x}}{ }^{2,3}$} \\
\cline { 2 - 3 } Tissue $^{1}$ & $\begin{array}{c}\text { Fibroblasts } \\
\text { Dissected }\end{array}$ & $\begin{array}{c}\text { Macrophages } \\
\mathbf{5}^{\mathbf{2}} \\
\text { Dissected }\end{array}$ \\
\hline$B R A F^{V 600 E}$ primary melanoma & $2 / 2$ & $1 / 1$ \\
$B R A F^{V 600 E}$ melanoma metastasis & $2 / 4$ & $2 / 4$ \\
Histologically tumor-free tissue & & $1 / 3$ \\
(from patients with $B R A F^{V 600 E}$ & $0 / 4$ & \\
melanoma) & & $0 / 1$ \\
$B R A F^{W T}$ primary melanoma & $0 / 4$ & \\
\hline
\end{tabular}

\footnotetext{
${ }^{1}$ Tissue samples were dual-stained either with melanoma antigen recognized by Tcells (MART1) and smooth muscle actin (SMA) or with MART1 and CD68 and

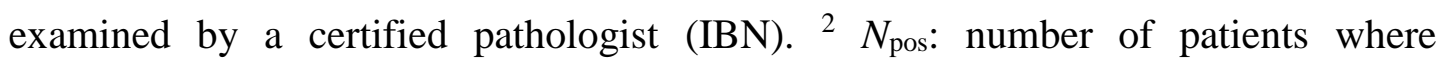
$B R A F^{V 600 E}$-positive peritumoral stromal cells were found; $N_{\mathrm{ex}}$ : the number of patients examined. ${ }^{3}$ Dissected cell samples were considered positive for $B R A F^{V 600 E}$ if the prevalence of the mutant allele was higher than $0.39 \%(\Delta \mathrm{Ct}<8) .{ }^{4}$ MART1-/SMA+ cells were considered fibroblasts. 5 MART1-/CD68+ cells were considered macrophages.
}

Table 1. Peritumoral fibroblasts and macrophages in BRAF ${ }^{V 600 E}$ melanoma carry the melanoma-derived BRAF ${ }^{V 600 E}$ mutation at the genetic level 
These results indicate that some peritumoral stromal cells contain a melanoma-derived oncogene at both the DNA and protein levels. The possible recurrent tumor-initiating potential of these cells is supported by our clinical observations of the local recurrence rate in our melanoma patients diagnosed before 1998. Patients who had primary melanoma removed completely, based on a clinical diagnosis of a non-melanoma skin lesion and with histologically tumor-free excision margins developed local recurrence significantly more often ( $p=0.7 \times 10^{-5}, 12$ out of 228 patients) than patients with melanomas excised with $5-\mathrm{cm}$ margins ( 8 out of 935 patients), implying that recurrent-tumor-initiating cells could indeed be present in the peritumoral stroma of malignant melanoma.

\section{Melanoma cells spontaneously fuse with fibroblasts and monocytes in vitro}

In order to investigate how cells displaying a stromal phenotype and containing melanomaderived genetic information could form, we co-cultured various human melanoma cell lines either with primary human dermal fibroblasts or with freshly isolated human monocytes for 24 hours. CellTracker Orange (CTO) and CellTracker Green (CTG) fluorescent vital dyes were used to identify melanoma cells and fibroblasts or monocytes, respectively (Figure 5).
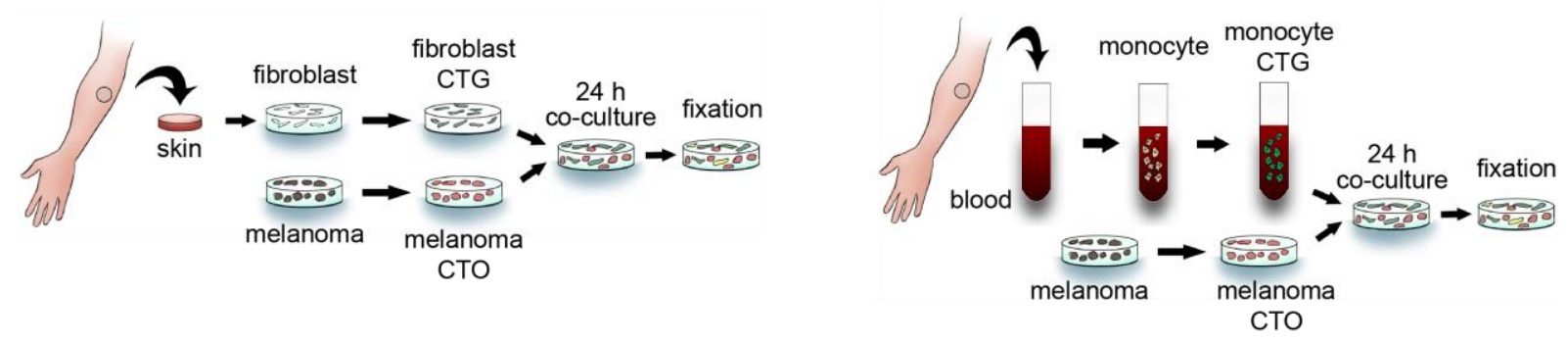

Figure 5. In vitro cell fusion model. Primary human dermal fibroblasts (left) or human peripheral blood-derived monocytes (right) labeled with CellTracker Green (CTG) were cocultured with human melanoma cells labeled with CellTracker Orange (CTO) for 24 hours. The samples were subsequently fixed and analyzed with a fluorescent microscope. 
After 24 hours, we observed the spontaneous formation of hybrid cells containing both CTO and CTG with laser scanning confocal microscopy. The subsequent three-dimensional reconstruction of such double positive cells demonstrated that the double fluorescence was detected in a single cell and did not derive from two overlapping cells (Figure 6a,b). To further confirm the fusion of melanoma cells and stromal cells at the genetic level, we used parental cells from donors of different genders and performed fluorescent in situ hybridization targeting the $\mathrm{X}$ and $\mathrm{Y}$ chromosomes in the hybrid cells to visualize and distinguish genetic material from both parental cells. For these experiments, A375 female melanoma cells were co-cultured with fibroblasts or monocytes from a male donor. A representative hybrid cell from each co-culture containing the sex chromosomes from both parental cells is displayed in Figure 6c,d. As also shown in Figure 6c, fluorescent in situ hybridization was performed on a cell that has been previously identified as a hybrid cell containing both CTO and CTG, suggesting that both methods can identify the same hybrid cell. 


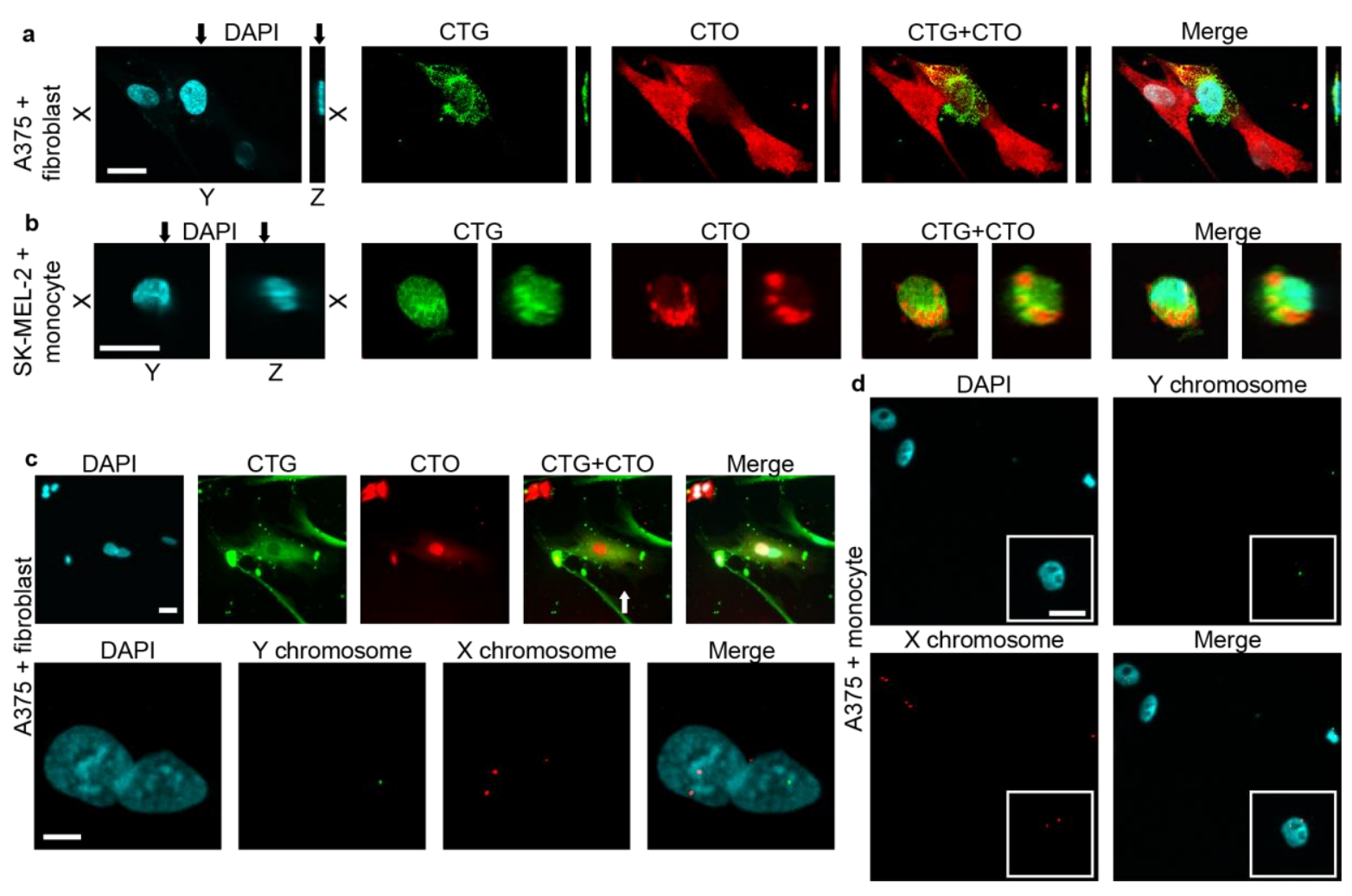

Figure 6. Melanoma cells spontaneously fused with primary human dermal fibroblasts and monocytes. (a,b) A melanoma (CTO)-fibroblast (CTG) (a) and a melanoma (CTO)-monocyte (CTG) (b) hybrid visualized with a confocal microscope in $X-Y$ and $X-Z$ planes. The Zstacking confirms that double positivity does not result from cells lying on each other. Black arrows indicate the crossline of planes; white bars indicate $20 \mu \mathrm{m}(\boldsymbol{a})$ and $10 \mu \mathrm{m}(\boldsymbol{b})$. (c) A melanoma (CTO)-fibroblast (CTG) hybrid confirmed with confocal microscopy contains a nucleus from a female melanoma cell and another from a fibroblast from a male donor (upper row). Fluorescent in situ hybridization visualizing three $X$ (red) and one $Y$ (green) chromosome in the same cell (lower row). White bars indicate $30 \mu \mathrm{m}$ (upper row) and $10 \mu \mathrm{m}$ (lower row). (d) Fluorescent in situ hybridization visualizing two $X$ (red) and one $Y$ (green) chromosome in a mononucleated melanoma (female)-monocyte (male) hybrid cell. White bar indicates $10 \mu \mathrm{m}$. 
To examine the possibility that the double positivity results from macrophages engulfing cell debris of dead melanoma cells, we used transwells in a set of co-culture experiments. The transwells separated the monocytes plated onto 12-well plates from the melanoma cells plated on the transwells and thereby inhibited cell fusion, which requires cell-cell contact but allowed phagocytosis of cell debris by monocytes. After 24 hours harvested cells were mixed and the rate of double positive cells in co-cultures with and without transwells was measured using flow cytometry. Since we observed some double positive events in the transwell cultures, we estimated the rate of hybrid cells by subtracting the rate of double positive cells detected in transwell cultures from that of co-cultures without transwells. In this way the proportion of hybrid cells in the different melanoma cell line - monocyte co-cultures varied between $0.5-4.39 \%$ (Figure 7-8).
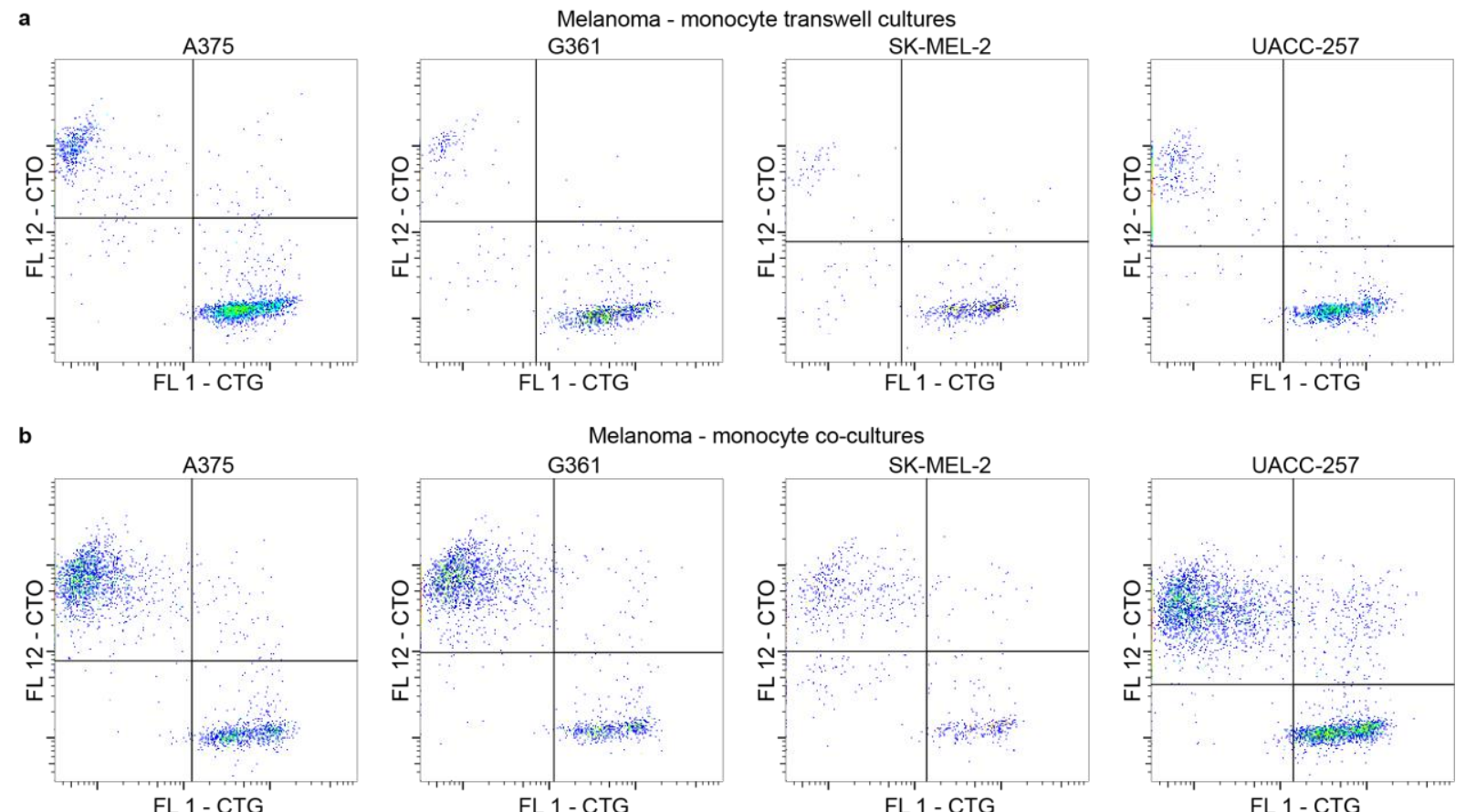

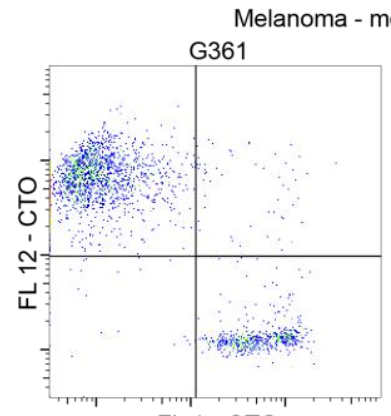

FL 1 - CTG

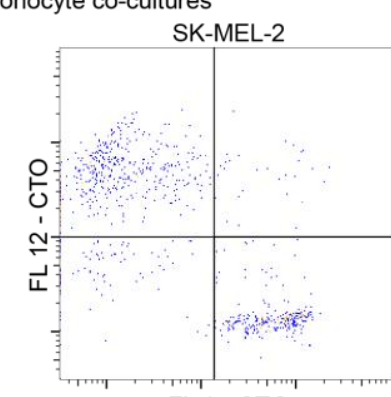

FL 1 - CTG

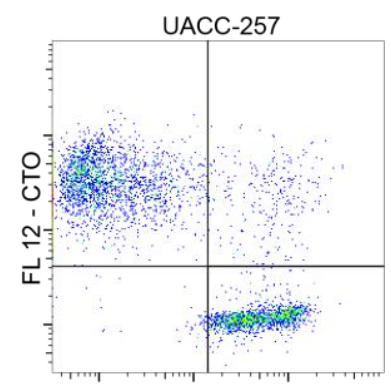

FL 1 - CTG

Figure 7. All investigated melanoma cell lines fuse spontaneously with human peripheral blood derived monocytes. Representative pseudocoloured dot plots of melanoma-monocyte co-cultures $(\boldsymbol{a})$ with and $(\boldsymbol{b})$ without transwells from three experiments. Since the different cells could only fuse in co-cultures but not in transwell cultures, fusion rate was determined as the rate of double positive cells detected in transwell cultures subtracted from that of cocultures. 


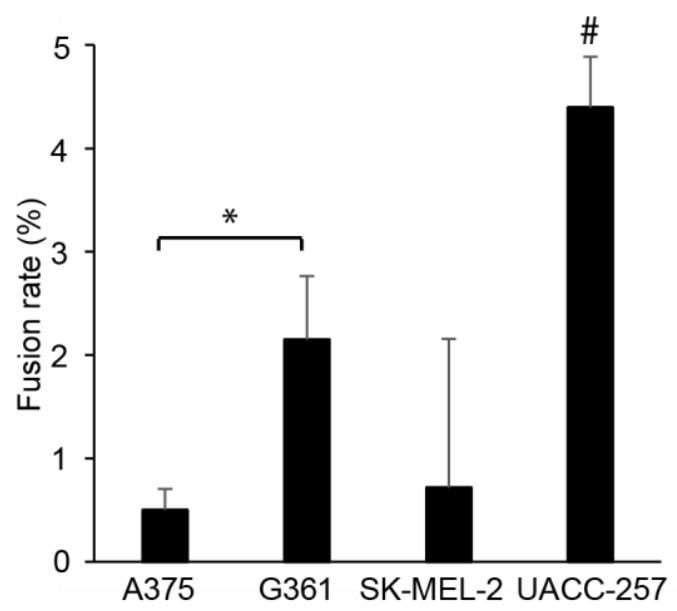

Figure 8. The percentage of hybrid cells compared to the total number of melanoma cells and monocytes after 24 hours of co-culture measured with flow cytometry. All investigated melanoma cell lines fused spontaneously with human peripheral blood-derived monocytes. Means of three experiments $+S D$ are shown. * indicates a significant difference between the marked groups; \# indicates a significant difference between the marked group and all the other groups. $p<0.05$. 
Hybrid cells are indistinguishable from stromal cells based on cell morphology and phenotype

Next, we examined the appearance of the hybrid cells and found that in all melanoma cell lines used for co-cultures, most of the hybrid cells were indistinguishable from fibroblasts or monocytes based merely on cell size and morphology (Figure 9-10).
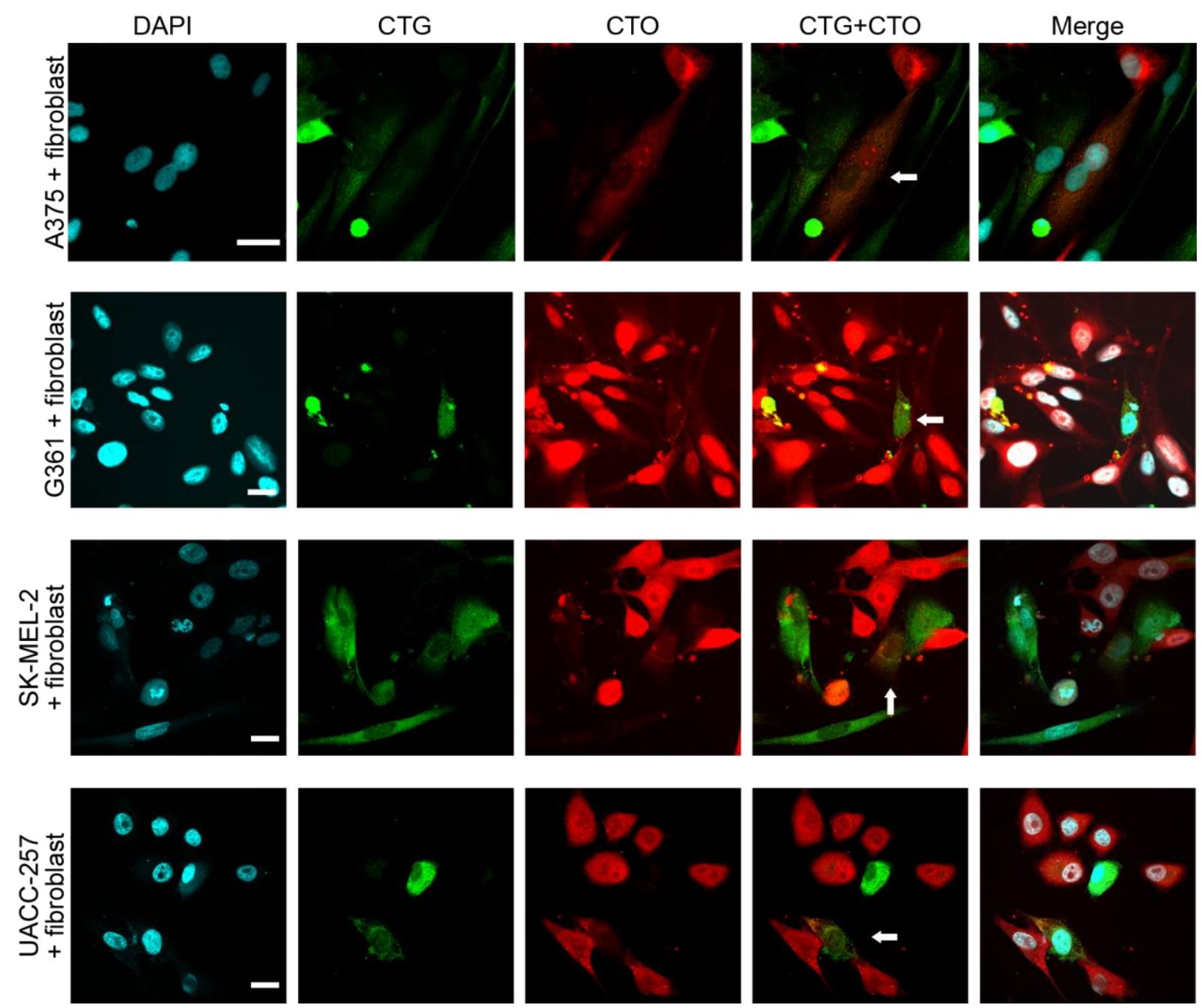

Figure 9. Melanoma-fibroblast hybrids are indistinguishable from stromal cells based on cell morphology. Spontaneously formed melanoma (CTO)-fibroblast (CTG) hybrids (white arrows) from different melanoma cell lines adopt the morphology of fibroblasts. White bars indicate $20 \mu \mathrm{m}$. 

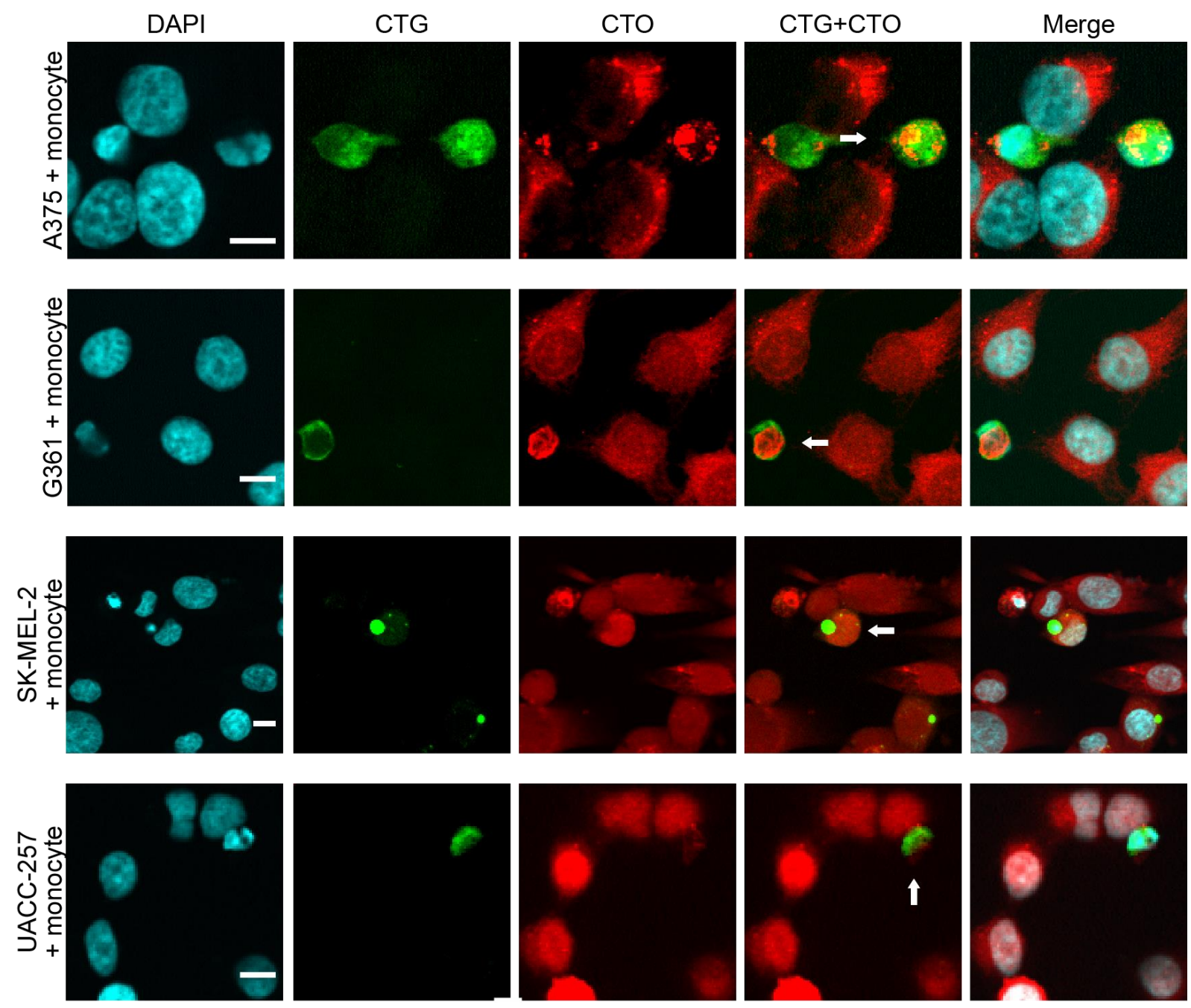

Figure 10. Melanoma-monocyte hybrids are indistinguishable from stromal cells based on cell morphology. Spontaneously formed melanoma (CTO)-monocyte(CTG) hybrids (white arrows) from different melanoma cell lines adopt the morphology of monocytes. White bars indicate $10 \mu \mathrm{m}$.

Moreover, all hybrid cells contained one or two nuclei, but no multinucleated cells were detected. Since hybrid cells could adopt the morphology of stromal cells and, more importantly, lose the characteristic morphology of melanoma cells, we examined commonly used phenotypic markers to better characterize the $\mathrm{CTG}+/ \mathrm{CTO}+$ hybrid cells and to investigate whether these markers enable their discrimination from conventional stromal cells. Interestingly, some melanoma-monocyte hybrids were positive for CD68 (Figure 11b). However, when the MART1-expressing G361 melanoma cell line was used, we detected hybrid cells that lost the expression of MART1 (Figure 11c-d) both in monocyte and in fibroblast co-cultures. These results provide evidence that spontaneously formed melanoma- 
stromal cell hybrids can adopt the morphology and phenotype of stromal cells while losing tumor-cell characteristics.

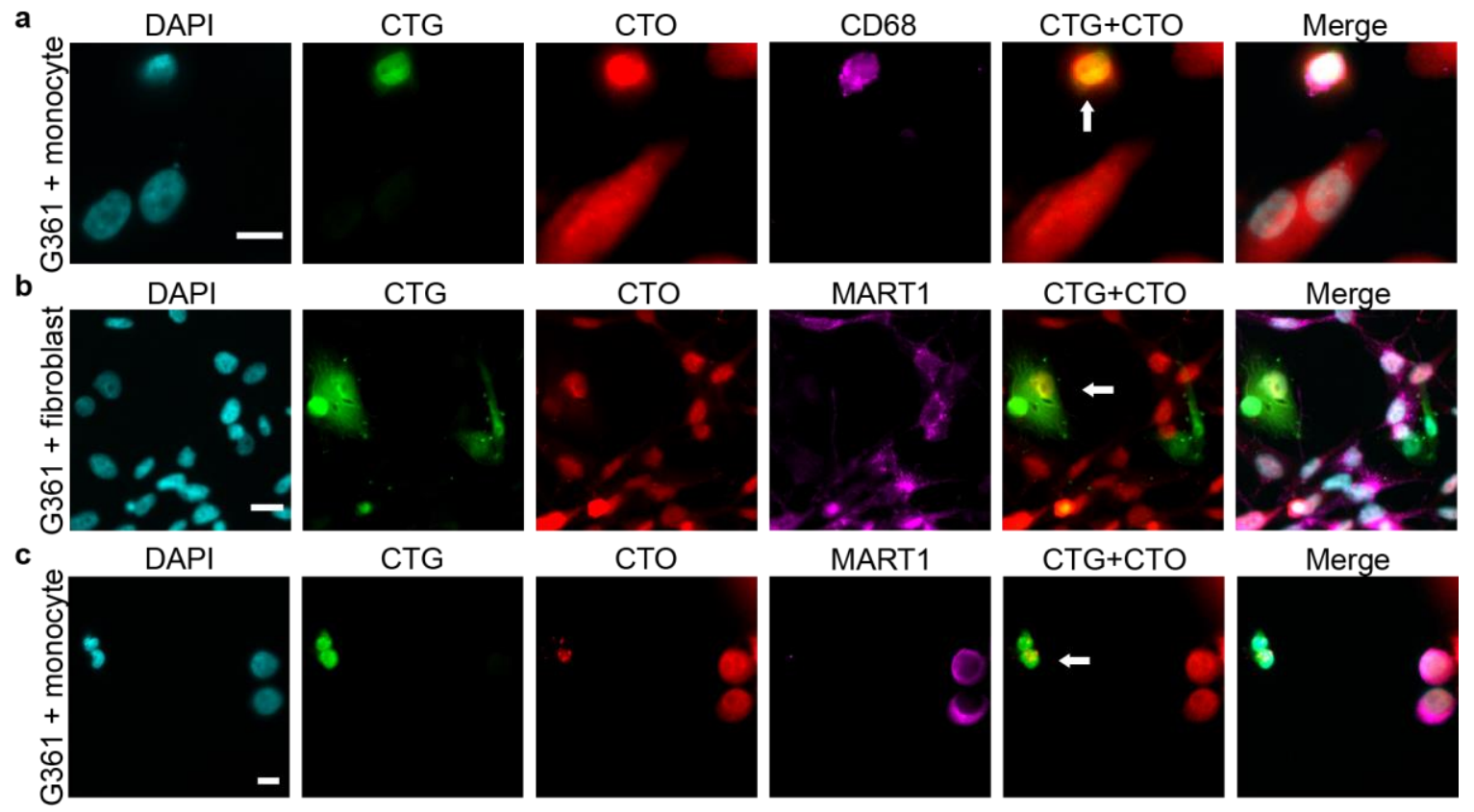

Figure 11. Melanoma-fibroblast and melanoma-monocyte hybrids are indistinguishable from stromal cells based on immunophenotype. (a) A melanoma (CTO)-monocyte (CTG) hybrid expressing the monocyte-macrophage marker CD68. (b,c) A melanoma (CTO)fibroblast (CTG) hybrid (b) and a melanoma (CTO)-monocyte (CTG) hybrid (c), which do not express the MART1 melanoma marker. White arrows indicate hybrid cells. White bars indicate $20 \mu \mathrm{m}$ in the case of fibroblasts (b) and $10 \mu \mathrm{m}$ in the case of monocytes (a,c). 


\section{DISCUSSION}

After the complete resection of primary cutaneous melanoma, patients occasionally develop local recurrence which is considered as an independent prognostic factor[1]. This can be explained by hidden tumor-initiating cells containing tumor-derived information as local minimal residual disease in the peritumoral area. In addition, such tumor-derived cells can also spread to distant areas such as lymph nodes and parenchymal organs.

Tumor cells are commonly identified during routine histological assessments using markers that are often insufficiently sensitive to distinguish tumor cells from stromal cells, which is supported by additional genetic analyses of sentinel lymph nodes[25]. The possible role of isolated tumor cells in the sentinel lymph node is debated, and the predictive value of additional diagnostic approaches, such as melanoma-marker detection at the mRNA level, to date, is inconclusive[26]. Nevertheless some studies using enhanced pathological assessments have found a link between the presence of single tumor cells in the sentinel lymph node and worse disease outcome compared to completely tumor-free sentinel lymph nodes[27-29] and other improved tumor detection methods, such as quantitative immunocytochemistry combined with single-cell comparative genomic hybridization, have been found to better predict patient survival and disease outcome[30]. The incomplete removal of tumor cells often results in a higher recurrence rate: small excision margins lead to a more frequent tumor recurrence, even if the excision margins are assessed to be tumor-free[2,31-33]. These data imply that recurrent-tumor-initiating cells with an altered phenotype could indeed be present in the peritumoral stroma of malignant melanoma, allowing them to remain undetected during routine diagnostic procedures.

In this study, we examined patient-derived melanoma tissue samples and detected peritumoral cells displaying stromal cell phenotype but carrying the oncogenic $B R A F^{V 600 E}$ mutation characteristic of the adjacent melanoma cells. First, we detected the mutated protein with a mutation-specific antibody. Even though nonspecific staining of the antibody in peritumoral mononuclear cells have been reported[34,35], the fact that peritumoral fibroblasts were also positive argues for a specific signal. Moreover, we only observed positivity in peritumoral cells adjacent to $B R A F^{V 600 E}$ melanoma but not in wild type. Nevertheless, to confirm the presence of the oncogene in these cells, we also performed genomic analyses and showed that the mutation is also present in cells with a stromal cell phenotype adjacent to $B R A F^{V 600 E}$ melanoma cells at the genetic level. We believe the mutation originates from tumor cells, as we did not detect the mutation in the stroma of $B R A F^{W T}$ melanoma samples. Possible 
mechanisms for the transfer of tumor-derived information to stromal cells include tumorstromal cell fusion, exosomal protein transfer and the phagocytosis of tumor debris. The obtained ex vivo results i.e. subpopulations of peritumoral stromal cells carrying the $B R A F^{V 600 E}$ mutation not only at protein but also at genomic level suggest that melanomastromal cell fusion may be one of the underlying mechanisms. It is important to mention that, since melanoma cells can lose MART1 expression, especially on the periphery of the tumor, cell morphology and the expression patterns of CD68 and SMA were all taken into account during the process of peritumoral cell identification.

In this paper, we show that human melanoma cells fuse with primary human fibroblasts and human peripheral blood-derived monocytes in vitro. By combining cytosolic intravital dyes and in situ hybridization techniques, we could identify the spontaneously formed hybrid cells between melanoma cells and primary stromal cells. This allows the studying of individual spontaneously formed hybrid cells, which is especially interesting, as there are currently no unique sets of markers to identify fused cells in vivo. There are only few reports on identifying fused cells in patients' biopsies[36,37]. These studies pre-select potential hybrid tumor cells using immunohistological approaches and confirm cell fusion events using genetic analyses. Therefore, further in vitro work is needed to further characterize and identify markers unique to hybrid cells that would allow their identification in vivo as well.

We demonstrate that the fusion takes place spontaneously with fusion rates of more than $0.1 \%$, which are surprisingly high compared to fusion rates reported in previous studies using electro- or chemical fusion followed by antibiotic selection. One possible explanation for the high fusion rates observed with flow cytometry is that most of the hybrid cells die shortly after formation[16], partly due to mitotic stress, and they may be very sensitive to any additional stress such as antibiotics or sorting. It should be noted that fusion rates in our hands varied significantly among different cell donors and even cell densities. Supposing that hybrid cells are formed constantly at a similar rate in vivo in an inflamed tumor microenvironment, even if the majority of the hybrid cells cannot survive, this rate should be sufficient for the detection of hybrid clones in vivo.

Several studies in mice[15] imply that cell fusion may also take place in human tumors in vivo. However, it is very difficult to detect tumor-stromal cell fusion on a genetic level in humans. To address this difficulty, tumors developing in patients who had received bone marrow transplants have been investigated: genetic material originating from the donor was detected in the patients' tumor cells[36,37], strongly suggesting a fusion event between 
recipient tumor cells and donor hemopoietic cells. However, inflammation resulting from treatment (e.g., whole body irradiation or chemotherapeutics) preceding bone-marrow transplantation has been reported to promote cell fusion[38-40]; therefore, further studies investigating fusion between tumor and stromal cells are clearly required.

We found that resulting hybrid cells can adopt the morphology and immunophenotype of stromal cells. Our results are in agreement with other studies proposing that tumor-stromal cell fusion can lead to the formation of hybrid cells displaying mesenchymal traits[14,41]. These findings highlight the fact that hybrid cells could acquire a stromal morphology and phenotype, which is especially interesting, as evidence for the presence of cell fusion in human cancer is from the detection of hybrid cells in the cancer but not the stromal compartments[36,37,42].

Cell fusion studies based on in vitro observations and mouse models suggest that cell fusion might contribute to tumor progression by increasing the tumor's metastatic potential and by inducing drug resistance[23,41,42] to certain tumor-stromal cell hybrid clones. In addition, tumor cells can acquire stem-cell-like properties by fusing with stromal cells[14,41]. Therefore, cell fusion might serve as an evolutionary mechanism for tumor cells to acquiring properties that allow them to react quickly to a changing environment, such as during chemotherapy or irradiation, or even to evade immune recognition. The malignant behavior of these tumor-stromal hybrid cells in mice is supported by the finding that, even though fusion hybrids of tumor cells and multipotent stromal cells first show a predominantly mesenchymal morphology, they subsequently undergo a reversal to a cancer-like phenotype and that these hybrid cells form invasive and metastatic tumors in mice[20]. However, the majority of in vitro spontaneously formed hybrid cells undergo apoptosis[16], most likely as a result of mitotic stress. Therefore, it is also possible that tumor-stromal cell fusion is rather an antitumor mechanism, eliminating most of the hybrid tumor cells but occasionally giving rise to highly malignant tumor cell clones. Furthermore, as our results suggest, cell fusion might provide an alternative mechanism for phenotype switching; thus, melanoma cells could become undetectable with standard histopathological methods that rely on the thorough examination of cell morphology and the expression of melanocytic markers.

Nevertheless, human in vivo studies demonstrating the relevance of tumor-stromal cell fusion in the clinical diagnosis or treatment of cancer have been missing.

In conclusion, our results suggest that peritumoral stromal cells contain melanoma-specific oncogenic properties such as the $B R A F^{V 600 E}$ mutation derived from the neighboring tumor 
cells, potentially as a result of cell fusion (Figure 12). In addition, we have here provided evidence that melanoma cells can adopt the phenotype of stromal fibroblasts and macrophages by spontaneous cell fusion in vitro. Although further studies are needed to functionally characterize these hybrid cells, based on literature data these cells can, following a reversal to a tumorous phenotype[20], possibly contribute to tumor recurrence. These cells are phenotypically indistinguishable from peritumoral stromal cells and are therefore not accurately detectable by routine histological assessments. Our results highlight the importance of genetic analysis and mutation-specific antibodies, especially in the case of histologically tumor-free tissue samples, for which improved methods for the detection of tumor cells have already been shown to better predict survival and outcome. Although yet to be confirmed in clinical trials, the use of genetic analyses and mutation-specific antibodies could have important prognostic and therapeutic consequences and could enable the detection of recurrent-tumor-initiating cells.

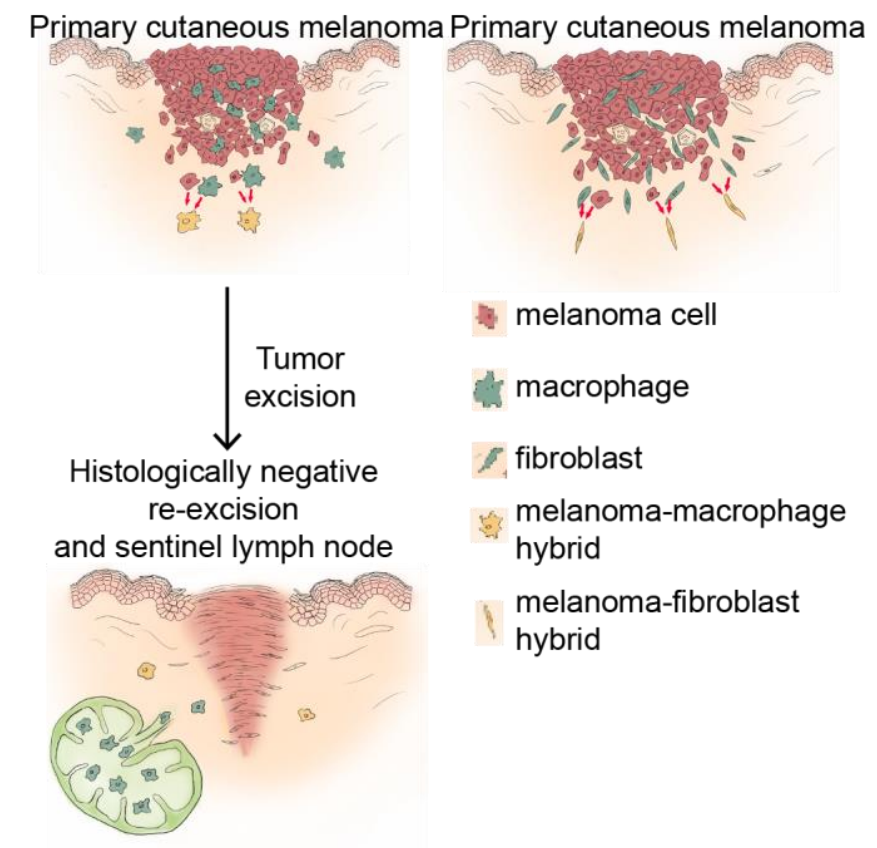

Figure 12. Melanoma cells (brown) fuse with peritumoral macrophages (green, upper left panel) and fibroblasts (green, upper right panel), giving rise to hybrid cells (yellow) with stromal cell morphology and phenotype, which carry melanoma-derived oncogenic mutations, such as BRAF ${ }^{V 600 E}$, and which may be sources of recurrent-tumor-initiating cells after the removal of the primary tumor (lower left panel). 


\section{SUMMARY}

Melanoma often recurs in patients after the removal of the primary tumor, suggesting the presence of tumor-initiating cells that are undetectable using standard diagnostic methods. As cell fusion has been implicated to facilitate the alteration of a cell's phenotype, we hypothesized that cells in the peritumoral stroma having a stromal phenotype that initiate recurrent tumors might originate from the fusion of melanoma and stromal cells.

Here, we showed that in patients with $B R A F^{V 600 E}$ melanoma, MART1-negative peritumoral stromal cells express $\mathrm{BRAF}^{\mathrm{V} 600 \mathrm{E}}$ protein. To confirm the presence of the oncogene at the genetic level, peritumoral stromal cells were microdissected and screened for the presence of $B R A F^{V 600 E}$ with a mutation-specific polymerase chain reaction. Interestingly, cells carrying the $B R A F^{V 600 E}$ mutation were not only found among cells surrounding the primary tumor but were also present in the stroma of melanoma metastases as well as in a histologically tumorfree re-excision sample from a patient who subsequently developed a local recurrence. We did not detect any $B R A F^{V 600 E}$ mutation or protein in the peritumoral stroma of $B R A F^{W T}$ melanoma. To investigate how such cells can form, we co-cultured melanoma cells with fibroblasts or monocytes. We showed that melanoma cells spontaneously fuse with human dermal fibroblasts and human peripheral blood monocytes in vitro. The hybrid cells' nuclei contained chromosomes from both parental cells and were indistinguishable from the parental fibroblasts or macrophages based on their morphology. Our results suggest that, by spontaneous cell fusion in vitro, tumor cells can adopt the morphology of stromal cells while still carrying oncogenic, tumor-derived genetic information.

In conclusion, these data suggest that some peritumoral stromal cells contain melanomaderived oncogenic information, potentially as a result of cell fusion. These hybrid cells display the phenotype of stromal cells and are therefore undetectable using routine histological assessments. Thus, our results highlight the importance of genetic analyses and the application of mutation-specific antibodies in the identification of potentially recurrent tumor-initiating cells, which may help better predict patient survival and disease outcome. 


\section{ACKNOWLEDGEMENTS}

I would like express my deep and sincere gratitude to my supervisor, István Balázs Németh, who, together with Prof. Lajos Kemény, the head of the Department of Dermatology and Allergology, provided me with their continuous, encouraging support and guidance throughout my work. Their enthusiasm, solid knowledge and scientific way of thinking have been of great value and a model for me.

I would also like to thank my friends and colleagues Lajos V. Kemény, Prof. Judit Oláh, Gergely Groma, Tünde Buknicz, Prof. Márta Széll, Attila Bebes, Erika Varga, Prof. Zsuzsanna Bata-Csörgö, Kornélia Szabó, Irma Korom, Barbara Gubán, Ádám Jakab, Hilda Polyánka, Anikó Göblös, and Gábor Tax for their endless help, emotional support and care, and for the many useful discussions and comments.

I am deeply grateful to Prof. Thomas Dittmar for introducing me to the field of cell fusion during my unforgettable visit in his lab and for his continuous, enthusiastic guidance and support throughout the previous years.

I would like to thank Erika Függ, Mónika Kohajda, Farkas Sükösd and Adrienn Hajdú for their inevitable technical support and assistance.

I am also grateful to Krisztina Buzás (Biological Research Center, Hungarian Academy of Science) for providing the cell lines, Ferhan Ayaydin (Biological Research Center) for not only providing the Fluoview 1000 microscope but also technical assistance, and Zoltán Tóbiás for preparing the illustrations.

This work was supported by TÁMOP-4.2.1/B-09/1/KONV-2010-0005 and by TÁMOP4.2.2/B grants. István B. Németh was supported by the Bolyai Scholarship, Hungarian Academy of Sciences. Thomas Dittmar was supported by the Fritz-Bender Foundation, Munich, Germany.

Lastly, I would like to thank to my family for all their endless patience, support and encouragement. I dedicate this thesis to them. 


\section{REFERENCES}

1. Hocevar, M.; Dragonja, Z.; Pilko, G.; Gazic, B.; Zgajnar, J. Residual melanoma after an excisional biopsy is an independent prognostic factor for local recurrence and overall survival. Eur. J. Surg. Oncol. J. Eur. Soc. Surg. Oncol. Br. Assoc. Surg. Oncol. 2014, doi:10.1016/j.ejso.2014.03.002.

2. Thomas, J. M.; Newton-Bishop, J.; A’Hern, R.; Coombes, G.; Timmons, M.; Evans, J.; Cook, M.; Theaker, J.; Fallowfield, M.; O’Neill, T.; Ruka, W.; Bliss, J. M. Excision Margins in High-Risk Malignant Melanoma. N. Engl. J. Med. 2004, 350, 757-766, doi:10.1056/NEJMoa030681.

3. Polyak, K.; Weinberg, R. A. Transitions between epithelial and mesenchymal states: acquisition of malignant and stem cell traits. Nat. Rev. Cancer 2009, 9, 265-273, doi:10.1038/nrc2620.

4. Landsberg, J.; Kohlmeyer, J.; Renn, M.; Bald, T.; Rogava, M.; Cron, M.; Fatho, M.; Lennerz, V.; Wölfel, T.; Hölzel, M.; Tüting, T. Melanomas resist T-cell therapy through inflammation-induced reversible dedifferentiation. Nature 2012, 490, 412-416, doi:10.1038/nature11538.

5. Giancotti, F. G. Mechanisms Governing Metastatic Dormancy and Reactivation. Cell 2013, 155, 750-764, doi:10.1016/j.cell.2013.10.029.

6. Thiery, J. P.; Acloque, H.; Huang, R. Y. J.; Nieto, M. A. Epithelial-mesenchymal transitions in development and disease. Cell 2009, 139, 871-890, doi:10.1016/j.cell.2009.11.007.

7. Easwaran, H.; Tsai, H.-C.; Baylin, S. B. Cancer epigenetics: tumor heterogeneity, plasticity of stem-like states, and drug resistance. Mol. Cell 2014, 54, 716-727, doi:10.1016/j.molcel.2014.05.015.

8. Stoecklein, N. H.; Klein, C. A. Genetic disparity between primary tumours, disseminated tumour cells, and manifest metastasis. Int. J. Cancer J. Int. Cancer 2010, 126, 589-598, doi:10.1002/ijc.24916.

9. Harkness, T.; Weaver, B. A.; Alexander, C. M.; Ogle, B. M. Cell fusion in tumor development: accelerated genetic evolution. Crit. Rev. Oncog. 2013, 18, 19-42.

10. Clawson, G. A. Cancer. Fusion for moving. Science 2013, 342, 699-700, doi:10.1126/science.1244270.

11. Lu, X.; Kang, Y. Cell fusion as a hidden force in tumor progression. Cancer Res. 2009, 69, 8536-8539, doi:10.1158/0008-5472.CAN-09-2159. 
12. Bjerkvig, R.; Tysnes, B. B.; Aboody, K. S.; Najbauer, J.; Terzis, A. J. A. Opinion: the origin of the cancer stem cell: current controversies and new insights. Nat. Rev. Cancer 2005, 5, 899-904, doi:10.1038/nrc1740.

13. Duelli, D.; Lazebnik, Y. Cell fusion: a hidden enemy? Cancer Cell 2003, 3, 445-448.

14. Xu, M.-H.; Gao, X.; Luo, D.; Zhou, X.-D.; Xiong, W.; Liu, G.-X. EMT and Acquisition of Stem Cell-Like Properties Are Involved in Spontaneous Formation of Tumorigenic Hybrids between Lung Cancer and Bone Marrow-Derived Mesenchymal Stem Cells. PLoS ONE 2014, 9, e87893, doi:10.1371/journal.pone.0087893.

15. Chakraborty, A. K.; Sodi, S.; Rachkovsky, M.; Kolesnikova, N.; Platt, J. T.; Bolognia, J. L.; Pawelek, J. M. A Spontaneous Murine Melanoma Lung Metastasis Comprised of Host × Tumor Hybrids. Cancer Res. 2000, 60, 2512-2519.

16. Wang, R.; Sun, X.; Wang, C. Y.; Hu, P.; Chu, C.-Y.; Liu, S.; Zhau, H. E.; Chung, L. W. K. Spontaneous Cancer-Stromal Cell Fusion as a Mechanism of Prostate Cancer Androgen-Independent Progression. PLoS ONE 2012, 7, e42653, doi:10.1371/journal.pone.0042653.

17. Dittmar, T.; Schwitalla, S.; Seidel, J.; Haverkampf, S.; Reith, G.; Meyer-Staeckling, S.; Brandt, B. H.; Niggemann, B.; Zänker, K. S. Characterization of hybrid cells derived from spontaneous fusion events between breast epithelial cells exhibiting stem-like characteristics and breast cancer cells. Clin. Exp. Metastasis 2011, 28, 75-90, doi:10.1007/s10585-010-93593.

18. Martin-Padura, I.; Marighetti, P.; Gregato, G.; Agliano, A.; Malazzi, O.; Mancuso, P.; Pruneri, G.; Viale, A.; Bertolini, F. Spontaneous cell fusion of acute leukemia cells and macrophages observed in cells with leukemic potential. Neoplasia N. Y. N 2012, 14, 10571066.

19. Helming, L.; Gordon, S. Molecular mediators of macrophage fusion. Trends Cell Biol. 2009, 19, 514-522, doi:10.1016/j.tcb.2009.07.005.

20. Rappa, G.; Mercapide, J.; Lorico, A. Spontaneous Formation of Tumorigenic Hybrids between Breast Cancer and Multipotent Stromal Cells Is a Source of Tumor Heterogeneity. Am. J. Pathol. 2012, 180, 2504-2515, doi:10.1016/j.ajpath.2012.02.020.

21. Lu, X.; Kang, Y. Efficient acquisition of dual metastasis organotropism to bone and lung through stable spontaneous fusion between MDA-MB-231 variants. Proc. Natl. Acad. Sci. U. S. A. 2009, 106, 9385-9390, doi:10.1073/pnas.0900108106.

22. Özel, C.; Seidel, J.; Meyer-Staeckling, S.; Brandt, B. H.; Niggemann, B.; Zänker, K. S.; Dittmar, T. Hybrid cells derived from breast epithelial cell/breast cancer cell fusion events 
show a differential RAF-AKT crosstalk. Cell Commun. Signal. CCS 2012, 10, 10, doi:10.1186/1478-811X-10-10.

23. Nagler, C.; Hardt, C.; Zänker, K. S.; Dittmar, T. Co-cultivation of murine BMDCs with $67 \mathrm{NR}$ mouse mammary carcinoma cells give rise to highly drug resistant cells. Cancer Cell Int. 2011, 11, 21, doi:10.1186/1475-2867-11-21.

24. Terada, N.; Hamazaki, T.; Oka, M.; Hoki, M.; Mastalerz, D. M.; Nakano, Y.; Meyer, E. M.; Morel, L.; Petersen, B. E.; Scott, E. W. Bone marrow cells adopt the phenotype of other cells by spontaneous cell fusion. Nature 2002, 416, 542-545, doi:10.1038/nature730. 25. Mocellin, S.; Hoon, D. S. B.; Pilati, P.; Rossi, C. R.; Nitti, D. Sentinel lymph node molecular ultrastaging in patients with melanoma: a systematic review and meta-analysis of prognosis. J. Clin. Oncol. Off. J. Am. Soc. Clin. Oncol. 2007, 25, 1588-1595, doi:10.1200/JCO.2006.09.4573.

26. Itakura, E.; Huang, R.-R.; Wen, D.-R.; Cochran, A. J. "Stealth” Melanoma Cells in Histology-Negative Sentinel Lymph Nodes. Am. J. Surg. Pathol. 2011, 35, 1657-1665, doi:10.1097/PAS.0b013e3182322cf7.

27. Satzger, I.; Völker, B.; Meier, A.; Schenck, F.; Kapp, A.; Gutzmer, R. Prognostic significance of isolated HMB45 or Melan A positive cells in Melanoma sentinel lymph nodes. Am. J. Surg. Pathol. 2007, 31, 1175-1180, doi:10.1097/PAS.0b013e3180341ebc.

28. Murali, R.; DeSilva, C.; McCarthy, S. W.; Thompson, J. F.; Scolyer, R. A. Sentinel lymph nodes containing very small $(<0.1 \mathrm{~mm})$ deposits of metastatic melanoma cannot be safely regarded as tumor-negative. Ann. Surg. Oncol. 2012, 19, 1089-1099, doi:10.1245/s10434-011-2208-z.

29. Murali, R.; Thompson, J. F.; Shaw, H. M.; Scolyer, R. A. The prognostic significance of isolated immunohistochemically positive cells in sentinel lymph nodes of melanoma patients. Am. J. Surg. Pathol. 2008, 32, 1106-1107; author reply 1107-1108, doi:10.1097/PAS.0b013e318162442e.

30. Ulmer, A.; Dietz, K.; Hodak, I.; Polzer, B.; Scheitler, S.; Yildiz, M.; Czyz, Z.; Lehnert, P.; Fehm, T.; Hafner, C.; Schanz, S.; Röcken, M.; Garbe, C.; Breuninger, H.; Fierlbeck, G.; Klein, C. A. Quantitative measurement of melanoma spread in sentinel lymph nodes and survival. PLoS Med. 2014, 11, e1001604, doi:10.1371/journal.pmed.1001604. 31. Ng, A. K.; Jones, W. O.; Shaw, J. H. Analysis of local recurrence and optimizing excision margins for cutaneous melanoma. Br. J. Surg. 2001, 88, 137-142, doi:10.1046/j.1365-2168.2001.01611.x. 
32. Hudson, L. E.; Maithel, S. K.; Carlson, G. W.; Rizzo, M.; Murray, D. R.; Hestley, A. C.; Delman, K. A. 1 or $2 \mathrm{~cm}$ margins of excision for T2 melanomas: do they impact recurrence or survival? Ann. Surg. Oncol. 2013, 20, 346-351, doi:10.1245/s10434-012-25438.

33. Pasquali, S.; Haydu, L. E.; Scolyer, R. A.; Winstanley, J. B.; Spillane, A. J.; Quinn, M. J.; Saw, R. P. M.; Shannon, K. F.; Stretch, J. R.; Thompson, J. F. The importance of adequate primary tumor excision margins and sentinel node biopsy in achieving optimal locoregional control for patients with thick primary melanomas. Ann. Surg. 2013, 258, 152-157, doi:10.1097/SLA.0b013e31828421e1.

34. Fisher, K. E.; Cohen, C.; Siddiqui, M. T.; Palma, J. F.; Lipford, E. H.; Longshore, J. W. Accurate detection of BRAF p.V600E mutations in challenging melanoma specimens requires stringent immunohistochemistry scoring criteria or sensitive molecular assays. Hum. Pathol. 2014, 45, 2281-2293, doi:10.1016/j.humpath.2014.07.014.

35. Long, G. V.; Wilmott, J. S.; Capper, D.; Preusser, M.; Zhang, Y. E.; Thompson, J. F.; Kefford, R. F.; von Deimling, A.; Scolyer, R. A. Immunohistochemistry is highly sensitive and specific for the detection of V600E BRAF mutation in melanoma. Am. J. Surg. Pathol. 2013, 37, 61-65, doi:10.1097/PAS.0b013e31826485c0.

36. Lazova, R.; LaBerge, G. S.; Duvall, E.; Spoelstra, N.; Klump, V.; Sznol, M.; Cooper, D.; Spritz, R. A.; Chang, J. T.; Pawelek, J. M. A Melanoma Brain Metastasis with a DonorPatient Hybrid Genome following Bone Marrow Transplantation: First Evidence for Fusion in Human Cancer. PLoS ONE 2013, 8, e66731, doi:10.1371/journal.pone.0066731.

37. Yilmaz, Y.; Lazova, R.; Qumsiyeh, M.; Cooper, D.; Pawelek, J. Donor Y chromosome in renal carcinoma cells of a female BMT recipient: visualization of putative BMT-tumor hybrids by FISH. Bone Marrow Transplant. 2005, 35, 1021-1024, doi:10.1038/sj.bmt.1704939.

38. Nygren, J. M.; Liuba, K.; Breitbach, M.; Stott, S.; Thorén, L.; Roell, W.; Geisen, C.; Sasse, P.; Kirik, D.; Björklund, A.; Nerlov, C.; Fleischmann, B. K.; Jovinge, S.; Jacobsen, S. E. W. Myeloid and lymphoid contribution to non-haematopoietic lineages through irradiationinduced heterotypic cell fusion. Nat. Cell Biol. 2008, 10, 584-592, doi:10.1038/ncb1721.

39. Espejel, S.; Romero, R.; Alvarez-Buylla, A. Radiation damage increases Purkinje neuron heterokaryons in neonatal cerebellum. Ann. Neurol. 2009, 66, 100-109, doi:10.1002/ana.21670.

40. Johansson, C. B.; Youssef, S.; Koleckar, K.; Holbrook, C.; Doyonnas, R.; Corbel, S. Y.; Steinman, L.; Rossi, F. M. V.; Blau, H. M. Extensive fusion of haematopoietic cells with 
Purkinje neurons in response to chronic inflammation. Nat. Cell Biol. 2008, 10, 575-583, doi:10.1038/ncb1720.

41. Ding, J.; Jin, W.; Chen, C.; Shao, Z.; Wu, J. Tumor Associated Macrophage $\times$ Cancer Cell Hybrids May Acquire Cancer Stem Cell Properties in Breast Cancer. PLoS ONE 2012, 7, e41942, doi:10.1371/journal.pone.0041942.

42. Shabo, I.; Midtbö, K.; Andersson, H.; Åkerlund, E.; Olsson, H.; Wegman, P.;

Gunnarsson, C.; Lindström, A. Macrophage traits in cancer cells are induced by macrophagecancer cell fusion and cannot be explained by cellular interaction. BMC Cancer 2015, 15, 922, doi:10.1186/s12885-015-1935-0. 